\title{
RADICAL ANNULATION METHODOLOQY. 2-VINYLCYCLOPENTANE DERIVATIVE FORMATION BY A 3 + 2 CYCLOADDITION REACTION
}

\author{
Radomir N. Salčić and Živorad Čeković*
}

Department of Chemistry, Faculty of Sciences, University of Belgrade, Studentski trg 16, P.0. Box 550, 11001 Belgrade, and Institut for Chemistry, Technology and Metallurgy,

Abstract: By thermally or photolytically induced decomposition of 0-acyl derivatives of $\mathrm{N}$-hydroxypyridine-2-thione or other thiohydroxamic esters, in the presence of an excess of electron deficient olefins, 2-vinylcyclopentane derivatives were obtained. This sequence of addition/cyclization/elimination reaction is mediated by a phenylthio radical.

Cyclopentane ring annulation by a $3+2$ radical cycloaddition reaction of 3-butenyl type radical 2 to the electron deficient olefins 1 represents a useful methodology for the construction of polysubstituted cyclic molecules $4 .{ }^{1-6}$ On the other hand a method for the free radical allylation by allyltributylstannanes ${ }^{\overline{7}}$ or allyl t-butylsulphide ${ }^{8}$ involving the addition of a carbon radical onto a double bond with concomitant displacement of a radical from the allylic position, has been applied on the radical cyclization reactions., 10 The cyclopentylmethyl radical 6 , generated by 5-exo-cyclization of 5-hexenyl type radical $\underline{5}$ and possesing a good radical leaving group in the allylic position, undergoes a $\beta-e l i-$ mination affording vinylcycloalkane derivatives $\underline{7} .3,5,6,9-11$

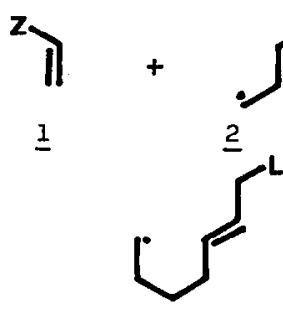

$\underline{5}$<smiles>[Z][C]CCCC=C</smiles>

$\underline{3}$<smiles>CCCC1CCCC1</smiles>

$\underline{6}$<smiles>[Z]C1CCCC1C</smiles>

$\underline{4}$<smiles>C=C[C]1CCCC1</smiles>

$?$

Our approach to the synthesis of highly functionalized vinylcyclopentane derivatives is based on the following known reactions: 1) intermolecular addition of 3-pentenyl radical 8 , ii) intramolecular cyclization of a 5-hexenyl type radical 9 , and iii) $B$-elimination of a phenylthio radical from the cyclopentylmethyl radical 10 , combining them in one reaction sequence which could be realized as one pot reaction. The reactivity of radical

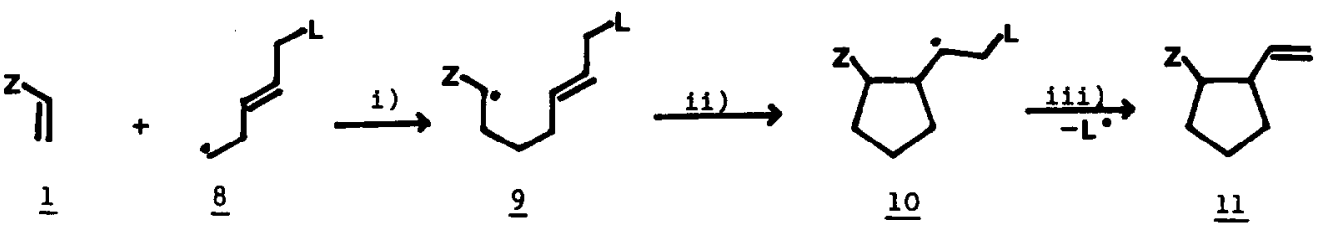


intermediates and the ratio of reagents were appropriately selected making possible two regiocontrolled $\mathrm{C}-\mathrm{C}$ bond formations. Thiohydroxamic esters were used as precursors of 3-pentenyl type radicals 8 . The Barton decarboxylation procedure ${ }^{12}$ was applied, because Curran generated 3-pentenyl type radical $\underline{8}$ by tributyltin hydride method and low yield of cyclic products were obtained. ${ }^{3}$ This sequence of radical cycloaddition reactions is terminated by elimination of a phenylthio radical which acts as a mediating species in this radical chain reaction.

Thiohydroxamic ester's 12 were prepared in sood yields as previously described. 12,13 By thermally or photolytically induced decomposition of thiohydroxamic esters (such as a 0-acyl derivatives of N-hydroxypyridine-2-thione 12) in the presence of five-fold molar

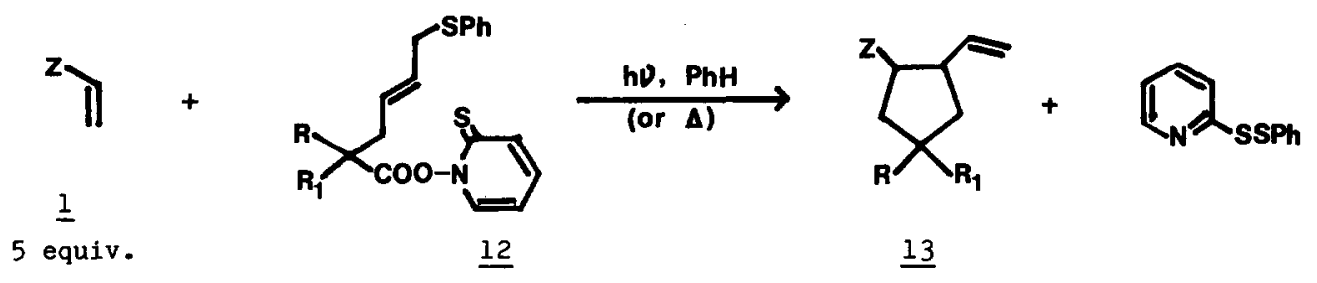

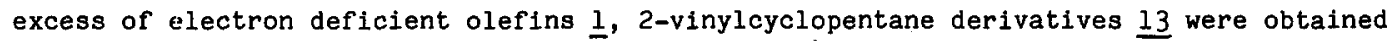
in $33-70 \%$ of isolated yields (50-90\% g.c. yields). ${ }^{14}$ The reaction products show the spectral characteristics consistent with the proposed structures. ${ }^{15}$ The products and their yields are presented in the Table 1.

The sequence of radical chain reactions involving an addition/cyclization/elimination is initiated by decomposition of esters of N-hydroxypyridine-2-thione and 6-phenylthio-3-

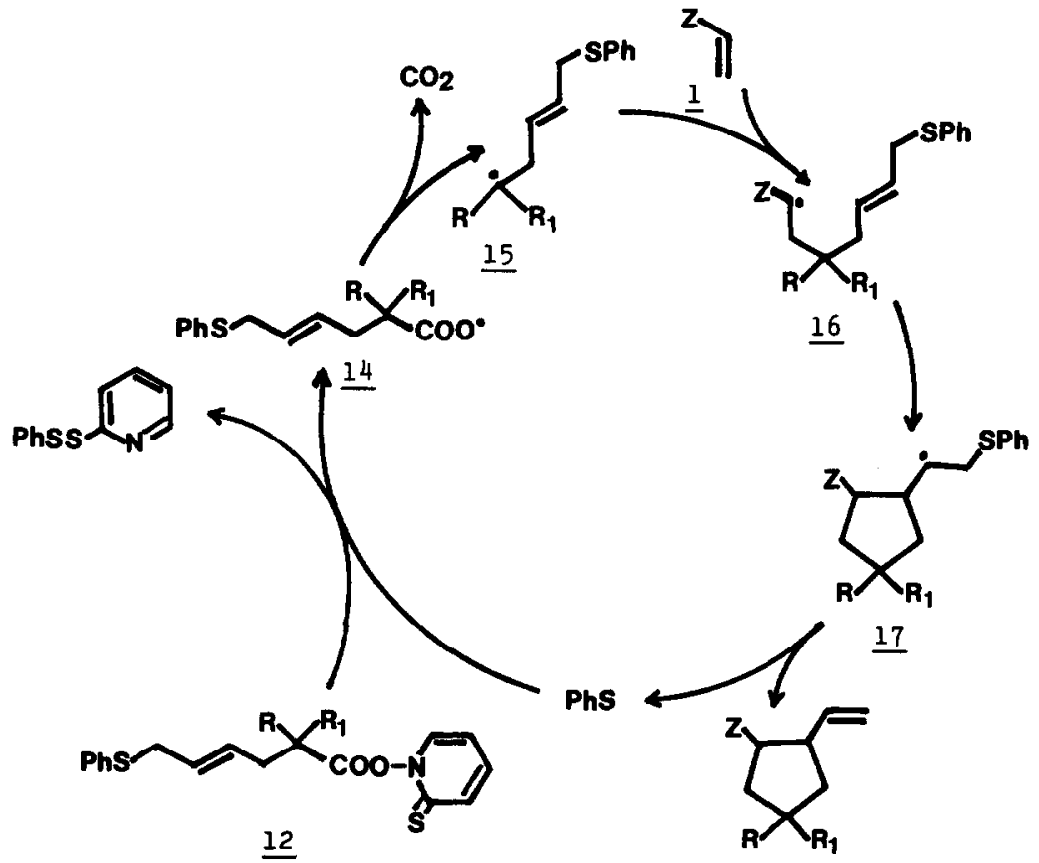




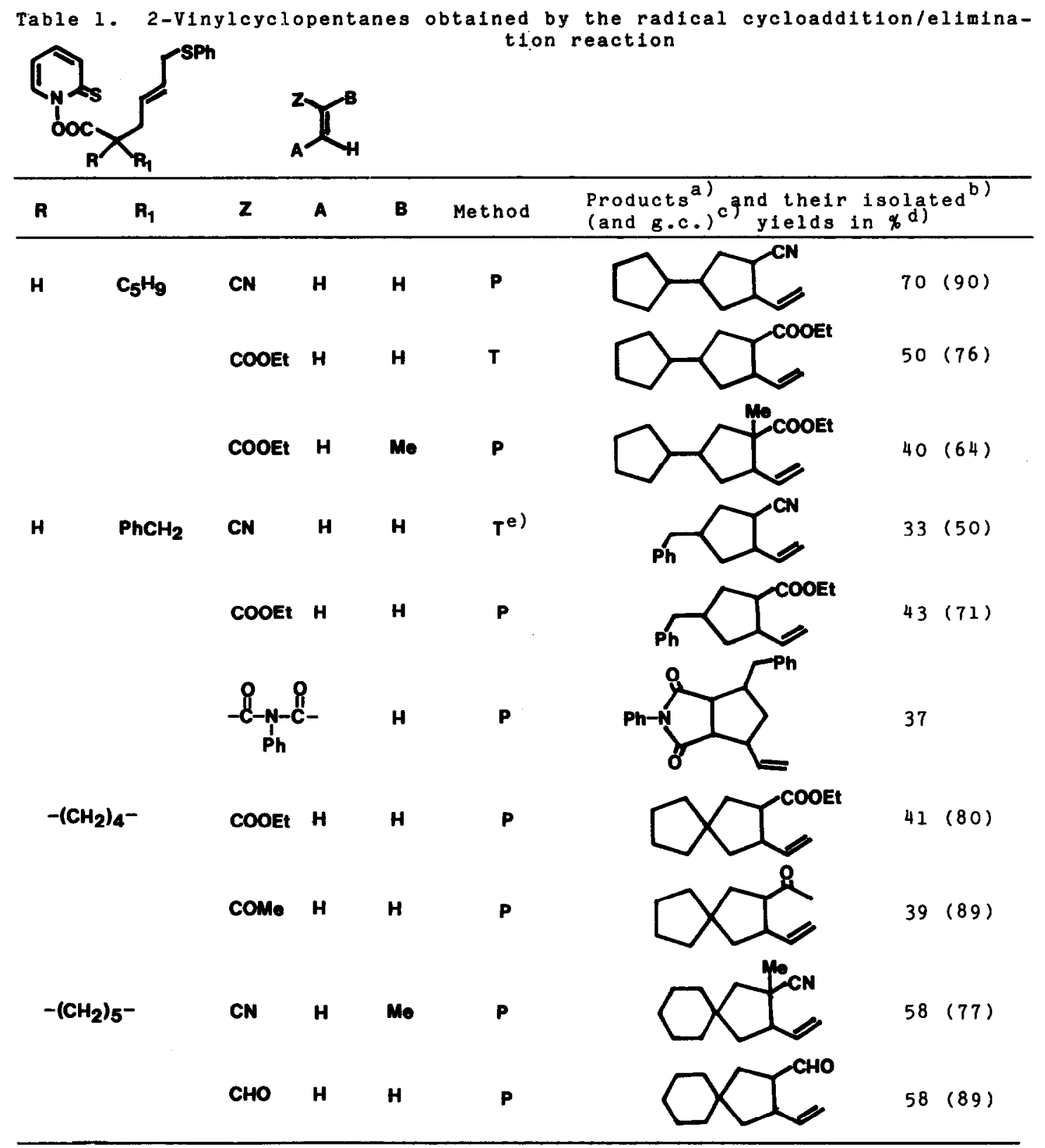

Method P: Irradiation of thiohydoxamic esters in benzene solution with a $200 \mathrm{~W}$ tungsten $\operatorname{lamp}(1 \mathrm{~h})$.

Method T: Thermal decomposition of esters in bolling toluene (about $112^{\circ} \mathrm{C}, 1 \mathrm{~h}$ ).

a) Mixtures of stereolsomers.

b) Isolated by chromatography using silica gel column and benzene as an eluent.

c) G.C. were performed using $5 \%$ OV-101 on Chronosorb WDMCS column.

d) Yields were not optimized. In some cases the experiments were repeated with reproducible yields of reaction products.

e) Thiohydroxamic ester

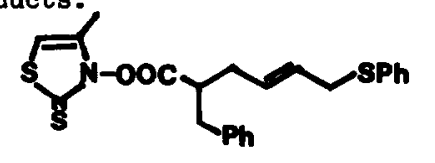

was used. 
hexenoic acid 12. Addition of the phenylthio radical to the $c=s$ bond of the starting ester 12 proceeds with a concerted or stepwise fragmentation reaction involving an intermediary carboxyl radical 14 , and by its decarboxylation a 5-phenylthio-3-pentenyl radical 15 is generated. In the following step a regioselective addition of radical 15 to the radicophilic olefin 1 occurs. Using 5 equivalnets of excess of olefin $\underline{1}$, the rate of addition of radical 15. to the electron deficient olefin 1 is more rapid than that for the addition to the starting thiohydroxamic ester 12 . Thus by 5-exo-cyclization of radical 16 , a cyclopentylmethyl radical 17 is formed. Bearing a phenylthio group in the $\beta$-position, radical 17 undergoes rapid fragmentation producing 2-vinylcyclopentane derivatives $\underline{13}$ and expelling the phenylthio radical as a chain carrying radical.

The synthetic value of this methodology is in the mild experimertal conditions and the possibility that different functional groups can be tolerated without considerable influence on the yields of the reaction products.

\section{References}

1. A. Ghosez, B. Giese, H. Zipse, C-Radikale, in Methoden der organischen Chemie, Houben-weil Band E 19a/Teil 2, Ed. M. Regitz, B. Giese, Georg Thieme Verlag, Stuttgart, 1989; D. P. Curran, Synthesis, 417 (Part 1), 489 (Part 2), (1988); B. Giese, Radicals in Organic Synthesis: Formation of Carbon-Carbon Bonds, Pergamon Press, Ed. J. A. Baldwin, Oxford 1986 ; M. Ramaiah, Tetrahedron, (Rep. No. 223), 43, 3541 (1987).

2. Ž. Ceković, R. Salčic, Tetrahedron Letters, 27, 5893 (1986); R. N. Saičić, Ź. Čeković, Tetrahedron, in press.

3. D. P. Curran, P. A. van Elburg, Tetrahedron Letters, 30, 2501 (1989); D. P. Curran, M.-H. Chen, E. Spletzer, C. M. Seong, C.-T. Chang, J. Am. Chem. Soc., 111,8872 (1989).

4. A. C. Angoh, D. L. J. Clive, J. Chem. Soc., Chem. Commun., 980 (1985).

5. K. Mira, K. Fugami, K. Oshima, K. Utimoto, Tetrahedron Letters, 29, 5135 (1988).

6. K. S. Feldman, A. L. Romane111, R. E. Ruckle, Jr., R. F. Miller, J. Am. Chem. Soc., 110, 3300 (1988); K. S. Feldman, A. K. K. Vong, Tetrahedron Letters, $31,823(1990)$.

7. G. E. Keck, J. B. Yates, J. Am. Chem. Soc., 104, 5829 (1982).

8. D. H. R. Barton, D. Crich, J. Chem. Soc., Perkin Trans. I, 1603, 1613 (1986); D. H. R. Barton, H. Togo, S. Z. Zard, Tetrahedron, 41, 5507 (1985).

9. T. A. Smith, G. Whitham, J. Chem. Soc., Chem. Commun., 897 (1985).

10. G. E. Keck, E. J. Enholm, Tetrahedron Letters, 26, 3311 (1985).

11. F. E. Ziegler, Zh.-L1 Zheng, Tetrahedron Letters, 28, 5973 (1987).

12. D. H. R. Barton, D. Crich, W. B. Motherwell, Tetrahedron, 41, 3901 (1985); J. Chem. Soc., Chem. Commun., 939 (1983); D. Crich, Aldrichimica Acta, 20, 35 (1987).

13. D. H. R. Barton, D. Bridon, I. Fernandez-Picot, S. Z. Zard, Tetrahedron, 43,2733 (1987); D. H. R. Barton, D. Crich, G. Kretzschmar, J. Chem. Soc., Perkin Trans. I, 39 (1986); D. H. R. Barton; D. Bridon, S. Z. Zard, Tetrahedron, 43, 5307 (1987).

14. Tipical experimental procedure: Thiohydroxamic esters were prepared in situ without isolation. The mixture of $2.4 \mathrm{mM}$ cf acyl chloride, $0.305 \mathrm{~g}(2.4 \mathrm{mM})$ of N-hydroxypyridine-2thione, $0.213 \mathrm{~g}(2.7 \mathrm{mM})$ of pyridine and $0.062 \mathrm{~g}(0.3 \mathrm{mM})$ of 4-dimethylaminopyridine in $10 \mathrm{ml}$ of benzene was stirred at room temperature during $15 \mathrm{~min}$. in an argon atmosphere and protected from light. To the prepared ester solution $0.636 \mathrm{~g}$ ( $12 \mathrm{mM}$ ) of acrylonitrile (or other electron deficient olefin) was added and the reaction mixture was irradiated at $r . t$. by a $200 \mathrm{~W}$ tungsten lamp during $1 \mathrm{~h}$ (or refluxed in toluene for $1 \mathrm{~h}$ ). After decomposition of 12 was completed an excess of solvent was removed by evaporation at reduced pressure and products were isolated by chromatography on silica gel column using benzene as an eluent.

15. Reaction products were characterized by ir, nmr and mass spectra and e.8. 2-vinyl-4-benzylcyclopentanecarbonitrile, has following spectral data: 1r: 2920, 2240, 1640, 1600, 1495 ,

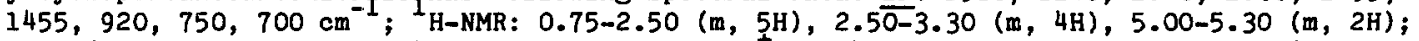
$5.55-6.20(\mathrm{~m}, 1 \mathrm{H}), 7.05-7.40(\mathrm{~m}, 5 \mathrm{H})$. MS: $211\left(\mathrm{M}^{+}\right), 184,155,117,91(100 \%), 77,65$. 